\title{
Management of desmoid-type fibromatosis involving peripheral nerves
}

\author{
Tratamento da fibromatose tipo desmoide envolvendo nervos periféricos \\ Mario G. Siqueira1, Paulo L. Tavares', Roberto S. Martins', Carlos O. Heise', Luciano H.L. Foroni', Marcelo \\ Bordalo², Roberto Falzoni3
}

\begin{abstract}
Desmoid-type fibromatosis is an uncommon and aggressive neoplasia, associated with a high rate of recurrence. It is characterized by an infiltrative but benign fibroblastic proliferation occurring within the deep soft tissues. There is no consensus about the treatment of those tumors. We present a surgical series of four cases, involving the brachial plexus (two cases), the median nerve and the medial brachial cutaneous nerve. Except for the last case, they were submitted to multiple surgical procedures and showed repeated recurrences. The diagnosis, the different ways of treatment and the prognosis of these tumoral lesions are discussed. Our results support the indication of radical surgery followed by radiotherapy as probably one of the best ways to treat those controversial lesions.
\end{abstract}

Key words: desmoid-type fibromatosis, desmoid tumor, fibromatosis, peripheral nerve.

\section{RESUMO}

A fibromatose do tipo desmoide é uma lesão tumoral agressiva e rara, associada a alto índice de recorrência. É caracterizada pela fibroblástica infiltrativa, porém benigna, que ocorre no interior de tecidos moles profundos. Não existe consenso com relação ao tratamento desses tumores. Apresentamos uma série cirúrgica de quatro casos comprometendo o plexo braquial (dois casos), o nervo mediano e o nervo cutâneo medial do braço. Com exceção do último caso, todos foram submetidos a múltiplos procedimentos cirúrgicos e apresentaram recorrências repetidas. São discutidos o diagnóstico, as diferentes formas de tratamento e o prognóstico dessas lesões tumorais. Nossos resultados apoiam o conceito de que cirurgia radical seguida por radioterapia é uma das melhores formas de se tratar essas controvertidas lesões.

Palavras-Chave: fibromatose tipo desmoide, tumor desmoide, fibroma, nervos periféricos.

Desmoid-type fibromatosis (DTF) is a fibrous proliferation from fascia and musculoaponeurotic tissues localized mainly in the abdomen. Owing to its slow growing and no risk of metastatization, these rare neoplastic lesions are regarded as benign, but the tendency of local invasion and the high rate of recurrence leads to significant morbidity by destruction of adjacent vital structures. There is no consensus about the best modality of treatment for these lesions, that ranges from wait-and-see and clinical treatment to radical surgery and radiotherapy. Due to the rarity of these tumors, evidence regarding the best treatment protocol for each case is drawn from case reports and small series of patients in the literature. The lesions involving or compressing peripheral nerves are even rarer and its ideal management has not been defined. In this report, we present four cases of desmoid-type fibromatosis involving the peripheral nerve. The different ways to manage these lesions are critically analyzed, and an attempt to define therapeutic suggestions is made.

\section{CASE REPORT}

\section{Case 1}

Male, 22-years-old, with a slow growing mass in the medial region of the right arm, immediately proximal to the medial epicondyle of the humerus, for seven years. In 1998, he was submitted to surgical treatment in another institution. The resection was reported as complete and the histological diagnosis was neurofibroma. In 2002, the tumor recurred and the same surgeon resected a 12 centimeters mass with firm adhesions

\footnotetext{
${ }^{1}$ Peripheral Nerve Surgery Unit, Department of Neurosurgery, University of São Paulo Medical School, São Paulo, SP, Brazil;

${ }^{2}$ Department of Radiology, University of São Paulo Medical School, São Paulo SP, Brazil;

${ }^{3}$ Department of Pathology, University of São Paulo Medical School, São Paulo SP, Brazil.

Correspondence: Mario G. Siqueira; Rua Maestro Cardim 592 / Conj. 1101; 01323-001 São Paulo SP - Brasil; E-mail: mgsiqueira@uol.com.br

Conflict of interest: There is no conflict of interest to declare.

Received 17 December 2011; Accepted 30 December 2011
} 
to the periosteum of the humerus and to other deep tissues, including the median and ulnar nerves. Once again, the histological diagnosis was of a neurofibroma. In 2004, a new recurrence, provoking local pain with irradiation to the distal ulnar nerve distribution, brought the patient to our institution. At examination, we observed two firm masses, one immediately proximal to the elbow and the other about 5 centimeters proximal and apart to the first one, both in the medial surface of the right arm (Fig 1). There were no neurological deficits. Two hardened masses with 10 and 11 centimeters in their largest diameters, with great adhesion to the adjacent muscles and apparent invasion in some areas, were founded at surgery. The ulnar nerve was dislocated inferior and medially, and the median nerve and the brachial artery were inside the proximal tumor. The resection was apparently complete and no additional neurological deficits were observed. The pain disappeared in the immediate postoperative period. The histological diagnosis now was of DTF. The patient refused any adjuvant treatment and one year after the last surgery a new lesion developed at the proximal limit of the surgical scar, without neurological impairment. Two solid masses, with 4 centimeters each in their largest diameters, extending to the axillary region, involving and compressing the median and ulnar nerves, were resected in the proximal arm. The limit of the lesions with the adjacent fibrosis and muscles was totally imprecise in some areas. After histological confirmation of recurrent DTF, the patient was submitted to complementary treatment with radiotherapy. After two years, the tumor recurred outside the radiation field, now in the infraclavicular area, and was removed once again. Since this last surgery, performed two years ago, the patient is doing well.

\section{Case 2}

Female, 33-years-old, had a previous resection of a left subcutaneous axillary nodule in another institution. We have no description of the procedure or of the mass histopathology. Fourteen months later, she was referred to us with a new axillary nodule, at the same site, complaining of pain, hypoesthesia and paresthesias in the medial aspect of the arm (medial brachial cutaneous nerve territory) and showing a tingling sensation evoked by percussion of the nodule. MRI demonstrated a nodular mass $(12 \times 8 \times 7 \mathrm{~mm})$ in the left axilla, well circumscribed, related to nervous structures, but without infiltrative characteristics. Intraoperatively, the nodule was involved by fibrous tissue, probably related to the previous procedure, and was compressing the medial brachial cutaneous nerve. The nerve was anatomically intact under the lesion. Total surgical removal was performed and, surprisingly, the histopathological diagnosis was DTF. The pain resolved and the patient is recovering her sensitive deficit. The patient is well, without recurrences, sixteen months after surgery.

\section{Case 3}

Female, 34-years-old, was submitted to resection of a right supraclavicular mass two years before in another institution, with a diagnosis of DTF. One year later, she had a recurrence in the same place, without associated neurological deficits or
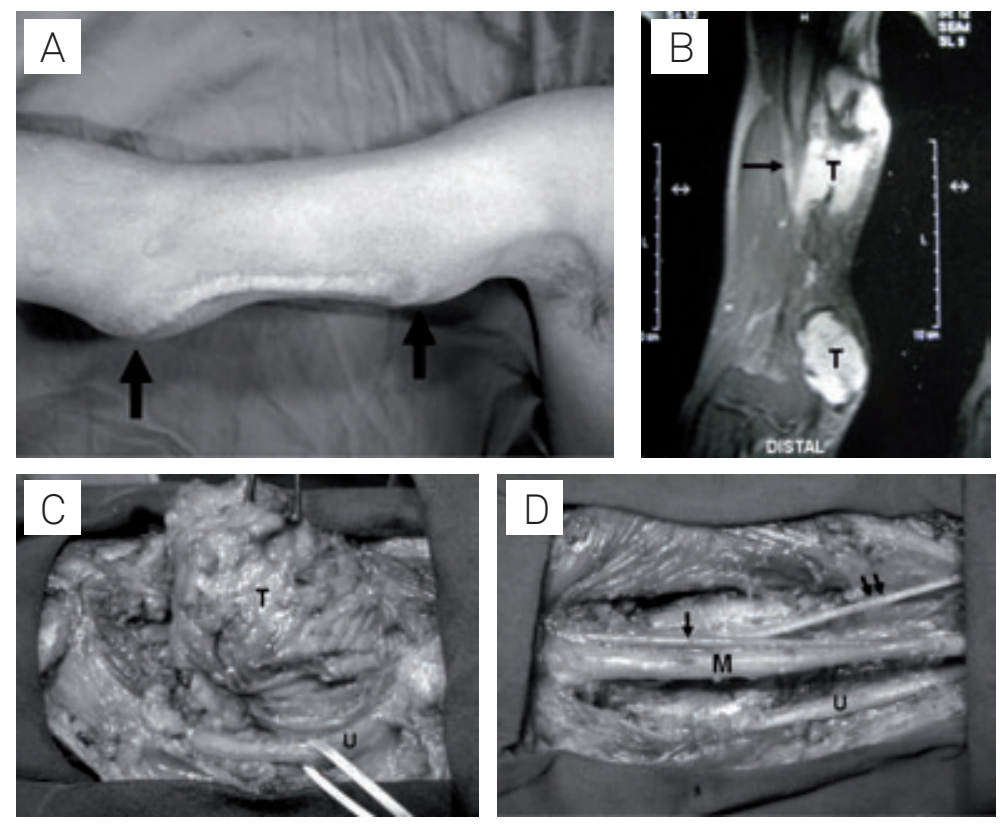

Fig 1. Case 1. (A) Two masses in the medial surface of the right arm (arrows), one immediately proximal to the elbow and the other about $5 \mathrm{~cm}$ proximal and apart to the first one. (B) Coronal T2-weighted MR image, with fat-supression, showing two masses with high signal intensity with areas of low signal intensity inside (possible fibrosis), localized in the proximal and distal thirds of the arm. Brachial artery (arrow); T: tumor. (C) Intraoperative photograph showing the distal tumor (T) dislocating the ulnar nerve $(U)$ and involving the median nerve (not shown). (D) Intraoperative photograph after removal of the tumor. Brachial artery (arrow); medial antebrachial cutaneous nerve (double arrow); M: median nerve; U: ulnar nerve. 
pain. The tumor was partially resected and the patient was referred to our hospital. On the first examination, the patient was neurologically intact and a voluminous mass was observed in her right supraclavicular region. Paresthesias were elicited by manipulation of the mass. The MRI showed a large lobulated mass $(8.5 \times 8.0 \times 5.0 \mathrm{~cm})$ compressing the anterior scalenus muscle and infiltrating the multifidus, levator scapulae and posterior scalenus muscles (Fig 2). The upper and middle trunks of the brachial plexus were involved, and the tumor dislocated the lower trunk, as well as the proximal segments of the internal jugular and subclavian veins. Gadolinium intravenous injection provoked a heterogeneous enhancement of the mass. A radical resection of the lesion was performed, without compromising the neurological status of the patient, and DTF diagnosis was confirmed. The surgery was soon followed by radiotherapy. The patient is still doing well after five years of follow-up, with no evidences of recurrence.

\section{Case 4}

Female, 19-years-old, had a right subscapular mass removed in 2005 and a right neck mass resected in 2006 in another institution. In both lesions the diagnosis of DTF was made. Five months later, the patient observed a growing mass in the area of the neck surgery. Except for mild local pain, the patient was asymptomatic. MRI demonstrated recurrence of both lesions, the subscapular measuring $6.5 \times 4.0 \times 2.0 \mathrm{~cm}$ and the cervical lesion with 9.0x7.0x3.0 cm. The posterior mass was located between the trapezius muscle and the right scapula. The right cervical lesion was medial to the sternocleidomastoid muscle and posterior to the internal jugular vein and carotid artery. The cervical mass was infiltrating the anterior and middle scalenus muscle and involved the $\mathrm{C} 7$ brachial plexus root and the phrenic nerve. Both lesions were radically resected, and, after the histological diagnosis of DTF, the patient was referred to the radiotherapy department. The patient is neurologically intact almost four years after the last surgery and there is no evidence of recurrence.

\section{DISCUSSION}

Over the years, many terms have been used to describe this tumor, including: desmoid tumor, well-differentiated nonmetastasizing fibrosarcoma, fibrosarcoma, Grade I fibrosarcoma, aggressive fibromatosis and desmoid-type fibromatosis (DTF), the last term being the designation of choice of the World Health Organization ${ }^{1}$. DTFs typically evolve over a period of three years and stabilize thereafter. Recurrences or progression most commonly occurs between 14 and 17 months after surgical resection ${ }^{2}$. It is estimated that these tumors account for $0.03 \%$ of all neoplasms and comprise around $3 \%$ of all soft tissue neoplasms ${ }^{3,4}$, with an annual occurrence of 2.4 to 4.5 new cases per million persons ${ }^{3}$, but the real incidence of DTF is difficult to ascertain, mainly because of the multiple denominations attributed to these lesions. In the largest published series of peripheral nerve tumors (Louisiana State University Health Sciences Center - 543 tumors), these lesions comprised only $2.0 \%$ of the cases $^{3,5}$.

Macroscopically, DTF is a rubbery gray-whitish lesion with a scar appearance, without a capsule, that can reach large
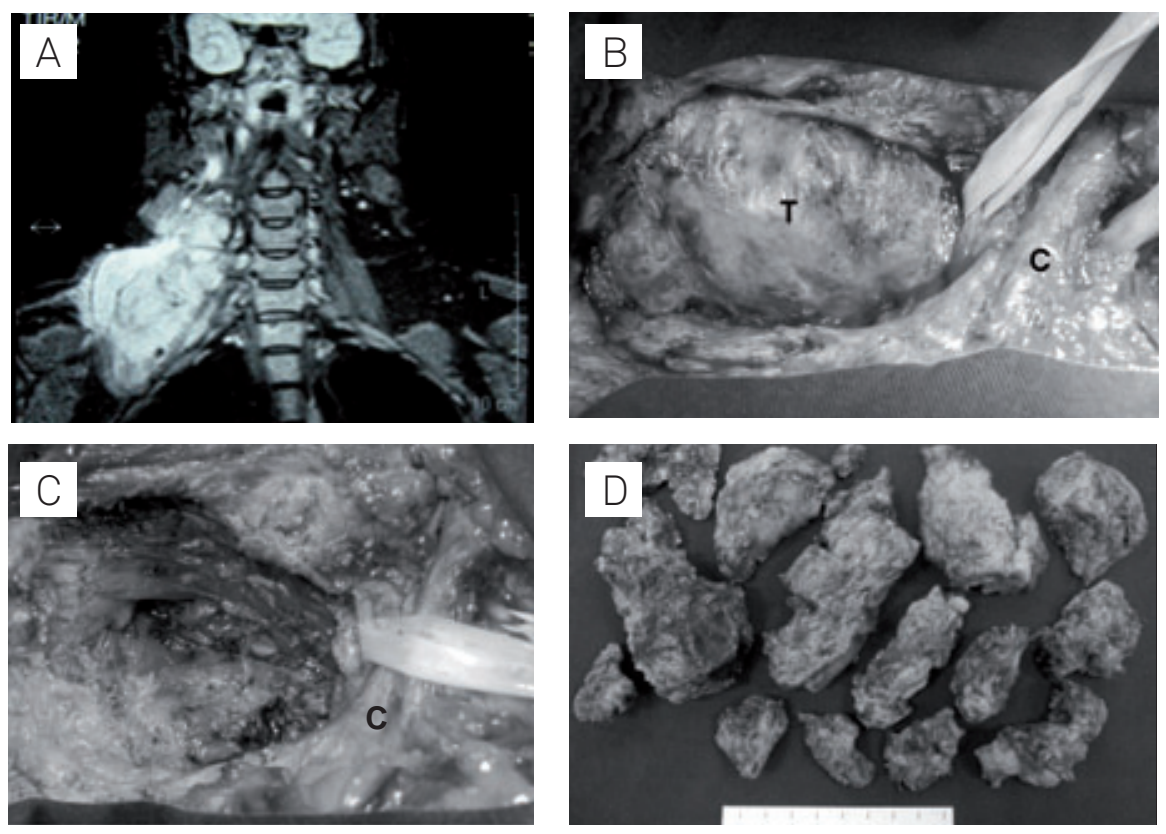

Fig 2. Case 3. (A) RM, Coronal T2-weighted MR image, with fat-supression, demonstrating a large mass with high signal intensity in the supraclavicular region, involving/dislocating the brachial plexus. (B). Intraoperative photograph demonstrating a large tumoral mass $(T)$ in the supraclavicular region. Penrose drains identifying brachial plexus elements. C: clavicle. (C) Intraoperative photograph after removal of the tumor. C: clavicle. (D) Macroscopic aspect of the tumor removed. 
dimensions (up to $20 \mathrm{~cm}$ ). Its histology is characterized by a local infiltrative process composed by mature fibroblasts or myofibroblasts in an abundant collagen matrix, without any evidence of cellular anaplasia or abnormal mitoses (Fig 3). Although regarded as benign lesions, DTFs are locally infiltrative. They usually invade the adjacent muscles and occasionally penetrate the trabecular spaces of bones in the area. They can also invade, involve or compress nerves and vessels, as in the cases we are reporting, and sometimes can grow inside scars. The destruction of adjacent vital structures and organs can cause extensive morbidity. The more aggressive lesions are characterized by a larger number of myofibroblasts, while the less aggressive show a larger number of mastocites. There is no report of regional linfonode involvement ${ }^{6}$.

First described in the abdominal wall of pregnant women, DTFs can occur virtually in any area of the body, but two thirds of these lesions are originated from the anterior aponeurosis of the rectus abdominis muscle ${ }^{2}$, and are frequently associated with the autosomal-dominant familial adenomatous polyposis of the colon (Gardner syndrome). The majority of the extraabdominal DTFs, frequently called aggressive fibromatosis, is originated from muscles/aponeurosis in the shoulder and pelvic girdles, and are solitary and sporadic ${ }^{7}$. Multicentric tumors, like our case \#4, are even more rare ${ }^{2}$. There are few reports of DTFs originated inside nerves, probably from stroma cells ${ }^{8}$. The DTFs resemble a fibrosarcoma for its infiltrative capacity, but they do not metastasize. These slow growing neoplasias, although with extremely rare occurrence of malignant degeneration, present a high incidence of recurrence, like in our cases \#1, 3 and 4, owing to its high propensity for local invasion?. The difficulty in performing an oncologic resection in most cases facilitates this high level of recurrence. Although the resection seems to be radical in many cases, the histological examination, as in our cases \#1,3 and 4, frequently demonstrates invasion of the adjacent tissues. The possible risk factors for recurrence include patient age, gender, tumor size, location, status of disease (primary or recurrent), surgical margins, limb/ girdle or intra-abdominal location, omission of radiotherapy, radiation dose less than $50 \mathrm{~Gy}$ and insufficient radiation field size (case \#1).

The etiology of the DTFs is unknown, despite trauma and endocrinological factors had been frequently implicated in its pathogenesis ${ }^{10}$. The age and sex of our patients is in accordance with the literature, as the process tends to involve a younger population (from puberty to 40 years) and to affect women more often. There is no ethnic prevalence.

The clinical presentation varies depending on the localization of the lesion. Usually, the patients search for medical care because of a slow growing mass, sometimes painful, that may compromise adjacent nerve and vascular structures, as in our cases.

Image evaluation of DTFs can be done by computed tomography (CT) or magnetic resonance imaging (MRI), the MRI being considered superior in evaluating the pattern of tumor growth, as well as the involvement of nearby structures. On CT scans, the lesion appears hyperattenuated with significant enhancement after contrast injection ${ }^{11}$. In MRI, the lesion appears hypointense to isointense relative to muscle on T1-weighted imaging, and with a signal intensity similar to fat on T2-weighted images ${ }^{12}$.

There is no consensus regarding the best treatment DTFs. Since it is a heterogeneous disease, treatment should be individualized to achieve local tumor control with concurrently acceptable morbidity and preservation of quality of life. At present, the management of patients with these tumors usually includes surgery, radiation therapy and cytotoxic and noncytotoxic chemotherapy.

All our patients were submitted to surgical resection, which is currently the mainstay treatment. When technically feasible, the ideal treatment would be an en bloc radical surgical excision of the lesion, with negative microscopic margins, even if this approach carries the risk of some functional and/or cosmetic compromise. Owing to the difficulty for the surgeon to clearly delineate the margins of the lesion due to the infiltrative
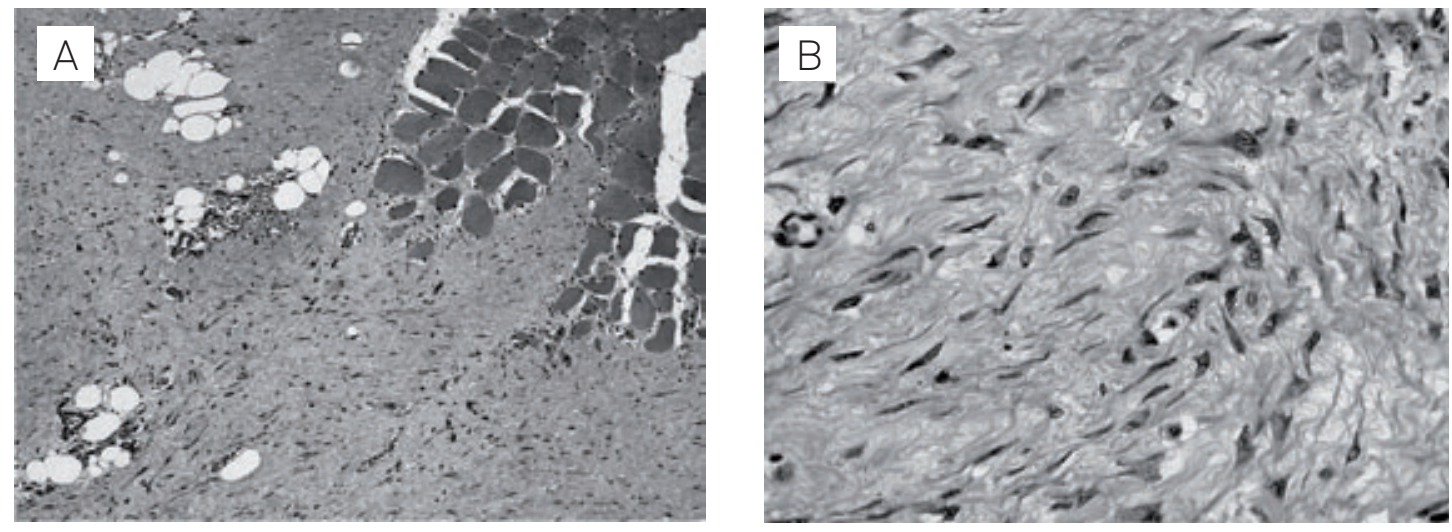

Fig 3. Photomicrograph of tissue from desmoid-type fibromatosis (Case 1), demonstrating: (A) Neoplastic proliferation of fibroblastic cells permeating skeletal muscle tissue and adipose tissue (100x HE); (B) Fibroblastic neoplastic cells in different stages of maturation, without atypias, necrosis or mitosis (400x HE). 
properties of the tumor, a margin of 2 to $3 \mathrm{~cm}$ beyond de edges of palpable tumor to achieve local control is advocated ${ }^{3}$, but in some special locations, like in the brachial plexus region (cases \# 3 and 4), this oncological approach is not possible without sacrificing important nerves and vessels ${ }^{7,13}$. The extension of the first resection seems to be the most important associated factor related to the level of recurrence ${ }^{14}$. Except for case \#2, all the others were operated before admission in our institution and we had no reliable information about the extension of the first or second resection. In the subtotal surgical resections, with positive microscopic margins, the incidence of recurrence can reach levels of $90 \%{ }^{15}$, but, even when resection with a wide surgical margin is achieved, the local recurrence rate remains high. Positive surgical margins after surgical resection are controversial as risk factors for tumor recurrence ${ }^{16}$. The importance of evaluating the risk/benefit ratio of obtaining a more extensive tumor resection at the expense of putting neurovascular structures at risk should be emphasized.

Despite its low mitotic index, DTFs have some radiosensitivity, and complementary treatment with radiotherapy (RT) has been used as the first treatment in patients who are not good surgical candidates ${ }^{17}$ and in some recurrence cases ${ }^{16}$. Although the results are quite variable, this type of treatment seems to lead to some local control ${ }^{18,19}$. The usual radiation doses (approximately $50 \mathrm{~Gy}$ ) and the application of modern, conformal radiation treatment planning techniques for the minimization of normal tissue dose, keeps the risk of complications at a low level ${ }^{20}$. Having in mind that the patients are usually young and otherwise healthy, and considering the normal tissue toxicity and potential late radiation effects, some researchers claim that RT should be pursued only in patients with gross residual disease $^{21}$. But, the higher incidence of recurrence in the cases that did not receive RT made some authors to change the approach and proceed with RT after the initial surgery ${ }^{22}$. Except for case \#2, a small and circumscribed lesion, all our patients received postoperative radiotherapy. Taking into account the long postoperative period without recurrence in cases \#3 and \#4, and the recurrence outside the radiation field in case \#1, this modality of treatment was apparently beneficial to our patients.

There are several recent reports in the literature indicating for the possibility of adjuvant medical therapy with cytotoxic chemotherapeutic agents used for sarcomas (methotrexate, cyclophosphamide, ifosamide, etoposide, cisplatin, vinblastine and doxorubicin) and with hormonal (noncytotoxic) chemotherapy (tamoxifen, testolactone, medroxyprogesterone) ${ }^{23-25}$. Hormonal therapy has been tried based on the female predominance of the disease and the finding that some of these tumors exhibit estrogen receptors. The evidence regarding the efficacy of these agents is drawn from small number of patients. When using this type of drug, one must remember that the probability of complications is reasonable and that the possibility of remission or stabilization of the disease in the literature does not surpass $50 \%^{25}$. This type of therapy should be reserved for the unresectable and recurrent cases. A drug that deserves special mention is the imatinib mesylate, a recently developed oral anticancer agent designed to selectively inhibit tyrosine kinases implicated in oncogenesis. Although the precise target and predictive factors for response to treatment in patients with DTFs are unknown, it seems that imatinib is active in the treatment of recurrent and progressive lesions, providing objective response and long-term stable disease in a large proportion of patients ${ }^{26}$.

There are also reports in the literature of the use of non-steroid anti-inflammatory drugs, oral contraceptives, vitamin $\mathrm{K}$, warfarin and vitamin $\mathrm{C}$, isolated or combined, as adjuvant therapy for these lesions ${ }^{27}$. Despite many of these therapies do not present definitive prove of its efficacy, they are frequently used in partially resected and recurrent lesions.

Recently, new modalities of treatment of DTFs like intraoperative electron radiotherapy ${ }^{28}$, radiofrequency ablation ${ }^{29}$ and cryoablation $^{30}$, have been reported. Although these treatments yielded good local control rates, their efficacy must be validated in a larger number of patients.

In summary, desmoid-type fibromatosis are neoplasms with an unpredictable biologic behavior, being difficult to affirm that they can be controlled. A treatment strategy should be idealized for each patient, however the analysis of our series and of the recent literature lead us to the conclusion that a radical surgical resection followed by radiation therapy seems to be the best protocol available at the moment. Long-term follow-up with imaging studies is always necessary to detect possible tumor recurrence.

\section{References}

1. Goldblum J, FletcherJA. Desmoid-type fibromatoses. In:Fletcher CDM, Unni KK, Mertens F (Eds). World Health Organization classification of tumours: pathology \& genetics of tumours of soft tissue and bone. Lyon: IARC Press; 2002:83-84.

2. Stoeckle E, Coindre JM, Longy M, et al. A critical analysis of treatment strategies in desmoids tumors: a review of a series of 106 cases. Eur J Surg Oncol 2009;35:129-134

3. Kim DH, Murovic JA, Tiel RL, Moes G, Kline DG. A series of 146 peripheral non-neural sheath nerve tumors: 30-year experience at Louisiana State University Health Sciences Center. J Neurosurg 2005;102:256-266

\footnotetext{
4. Myhre-Jensen O. A consecutive 7-year series of 1331 benign soft tissue tumors. Clinicopathologic data. Comparison with sarcomas. Acta Orthop Scand 1981;52:287-293.

5. Kim DH, Murovic JA, Tiel RL, Moes G, Kline DG. A series of 397 peripheral neural sheath tumors:30-year experience at Louisiana State University Health Sciences Center. J Neurosurg 2005;102:246-255.

6. Plaat BE, Balm AJ, Loftus BM, Gregor RT, Hilgers FJ, Keus RB. Fibromatosis of the head and neck. Clin Otolaryngol Allied Sci 1995;20:103-108.

7. Enzinger FM, Weiss SW. Soft tissue tumors. 2 ed. St. Louis: CV Mosby; 1988:152-154.
} 
8. Ferraresi S, Garozzo D, Bianchini E. Aggressive fibromatosis (desmoid tumor) of the radial nerve: favorable resolution. Case report. J Neurosurg 2001;95:332-333.

9. Miralbell R, Suit HD, Mankin HJ, Zuckerberg Lr, Stratcher MA, Rosenberg AE. Fibromatoses: from postsurgical surveillance to combined surgery and radiation therapy. Int J Radiat Oncol Biol Phys 1990;18:535-540.

10. Tonelli F, Valanzano R, Brandi ML. Pharmacologic treatment of desmoid tumors in familial adenomatous polyposis: results of an in vitro study. Surgery 1994;115:473-479.

11. Abdelkader M, Riad M, Williams A. Aggressive fibromatosis of the head and neck (desmoid tumors). J Laryngol Otol 2001;115:772-776.

12. VandevenneJE, De SchepperAM, De Beuckeleer L, et al. New concepts in understanding evolution of desmoid tumors: MR imaging of 30 lesions. Eur Radiol 1997;7:1013-1019.

13. Goubier JN, Teboul F, Oberlin C. Tumeurs desmoides et plexus brachial. Chir Main 2003;22:203-206.

14. Gaposchkin CG, Bilsky MH, Ginsberg R, Brennan MF. Function-sparing surgery for desmoid tumors and other low-grade fibrosarcomas involving the brachial plexus. Neurosurgery 1998;42:1297-1301.

15. Acker JC, Bossen EH, Halperin EC. The management of desmoid tumors. Int J Radiat Oncol Biol Phys 1993;26:851-858.

16. Huang PW, Tzen CY. Prognostic factors in desmoids-type fibromatosis: a clinicopathological and immunohistochemical analysis of 46 cases. Pathology 2010;42:147-150.

17. Nuyttens JJ, Rust PF, Thomas CR Jr, Turrisi AT. Surgery versus radiation therapy for patients with aggressive fibromatosis or desmoids tumors: a comparative review of 22 articles. Cancer 2000;88:1517-1523.

18. Goy BW, Lee SP, Eilber F, et al. The role of adjuvant radiotherapy in the treatment of resectable desmoid tumors. Int J Radiat Oncol Biol Phys 1997;39:659-665.

19. Plukker J, Oort I, Vermey A, et al. Aggressive fibromatosis: therapeutic problems and the role of adjuvant radiotherapy. $\mathrm{Br} \mathrm{J}$ Surg 1995;82:510-514

20. Micke O, Seegenschmiedt MH. Radiation therapy for aggressive fibromatosis (desmoids tumors): results of a national patterns of care study. Int J Radiat Oncol Biol Phys 2005;61:882- 891.

21. Wong SL. Diagnosis and management of desmoids tumors and fibrosarcoma. J Surg Oncol 2008;97:554-558.

22. Seinfeld J, Kleinschmidt-DeMasters BK, Tayal S, Lillehei KO. Desmoidtype fibromatosis involving the brachial plexus. Neurosurg Focus 2007;22:E22.

23. Wilcken N, Tattersall MH. Endocrine therapy for desmoid tumors. Cancer 1991;68:1384-1388.

24. Constantinidou A, Jones RL, Scurr M, Al-Muderis O, Judson I. Advanced aggressive fibromatosis: Effective palliation with chemotherapy. Acta Oncol 2011;50:455-461.

25. Wilcken N, Tattersall MH. Endocrine therapy for desmoid tumors Cancer 1991;68:1384-1388.

26. Chug R, Wathen JK, Patel SR, et al. Efficacy of imitinib in aggressive fibromatosis: Results of a phase II multicenter Sarcoma Alliance for Research through Collaboration (SARC) trial. Clin Cancer Res 2010;16:4884-4891.

27. Wadell WR, Kirsch WM. Testolactone, sulindac, warfarin, and vitamin K, for unresectable desmoid tumors. Am J Surg 1991;161:416-421

28. Timke C, Oertel S, Hensley FW, et al. Intraopertaive electron radiotherapy for the management of aggressive fibromatosis. Int $\mathrm{J}$ Radiat Oncol Biol Phys 2010;76:1154- 1160.

29. Ilaslan H, Schils J, Joyce M, Marks K, Sundaram M. Radiofrequency ablation: another treatment option for local control of desmoids tumors. Skeletal Radiol 2010;39:169-173.

30. Kujak JL, Liu PT, Johnson GB, Callstrom MR. Early experience with percutaneous cryoablation of extra-abdominal desmoids tumors. Skeletal Radiol 2010;39:175-182. 